\title{
Effects of impulse noise and continuous steady state noise on hearing
}

\author{
S MÄNTYSALO AND J VUORI \\ From the Institute of Occupational Health, Department of Psychology, 00290 Helsinki, Finland
}

\begin{abstract}
In this study the effects on hearing induced by occupational exposure to impulse noise were compared with those induced by exposure to continuous steady state noise. Three groups exposed to impulse noise, one group exposed to continuous steady state noise, and an unexposed control group were studied. The hearing thresholds of the groups were measured by a puretone audiometer three times in two workdays. None of the groups showed significant differences between the hearing thresholds measured in the morning, at midday, and in the afternoon. Group 1 . with the shortest duration of exposure and group 2 with the intermediate duration of exposure to impulse noise had the highest thresholds at $6000 \mathrm{~Hz}$ in both ears. Group 3 with the longest duration of exposure to impulse noise had the highest thresholds asymmetrically, at $4000 \mathrm{~Hz}$ in the left ear and at $6000 \mathrm{~Hz}$ in the right ear. The group exposed to continuous steady state noise also had the highest thresholds asymmetrically, in the left ear at $6000 \mathrm{~Hz}$. It was concluded that the longer the duration of exposure to impulse noise the wider the region of the frequencies that showed raised threshold shifts in both ears. Impulse noise seemed to produce permanent threshold shifts at 4000 and $6000 \mathrm{~Hz}$ after a shorter duration of exposure than continuous steady state noise.
\end{abstract}

Noise is one of the greatest hazards of work and the National Board of Occupational Safety and Health has estimated that $25-30 \%$ of working Finns are exposed to excessive noise. ${ }^{1}$

Experience has shown that impulse noise may be more harmful to hearing than continuous, steady state noise. ${ }^{2}$ The criteria for hearing damage induced by steady state noise are well established, but it is uncertain whether the established criteria are also valid for exposure to impulse noise. ${ }^{34}$

The quality of impulse noise as an auditory stimulation differs from that of continuous noise. Impulse noise that results from hammering, stamping, pressing, and gunfire can be characterised by its instantaneous, short duration. In conditions where several workers hammer, press, or chisel impulses may occur abruptly and randomly in varying frequencies at the rate of several tens per second.

In perception psychology a hearing threshold is the value given to the scale of intensity or the pitch of a tone stimulus which is the minimum sufficient to cause the sensation of tone stimulus. The hearing threshold in man varies with the frequency of the

Received 8 October 1982

Accepted 6 December 1982 sound, the greatest sensitivity being in the range of $4000 \mathrm{~Hz}$. Intense sound stimulation can raise the hearing threshold and temporarily induce impaired hearing (NITTS). The hearing of those who work in noisy environments may be imparied by about 30 $\mathrm{dB}$, such impairment resulting from the raised hearing thresholds caused by eight hours of exposure to 90-100 dB continuous noise. ${ }^{5}$ The corresponding raised thresholds caused by eight hours of exposure to impulse noise may be as high as $50 \mathrm{~dB} .^{6}$

The cumulative effects of long periods of exposure to high noise levels may also lead to a noise induced permanent threshold shift (NIPTS) and to permanently impaired hearing. Exposure for 10-15 years to high levels of continuous industrial noise seems to raise thresholds at about $4 \mathrm{kHz}^{78}$ Exposure to high levels of impulse noise can induce hearing loss in a much shorter time and can be seen within a wider range of frequencies. ${ }^{9}$ The International Organisation for Standardisation defines the risk of work noise induced hearing loss as the percentage of workers whose hearing thresholds are raised because of noise, on average, $25 \mathrm{~dB}$ at frequencies of 500,1000 , and $2000 \mathrm{~Hz}^{3}$ At present noise induced hearing loss comprises about half the verified cases of occupational diseases in Finland if 
occupational skin diseases are excluded from the statistics. $^{10}$

The purpose of this study was to compare the hearing effects induced by exposure to impulse noise with those induced by exposure to continuous steady state noise. In addition the effects of daily exposure to both types of noise were compared by testing the hearing thresholds of groups of workers several times during the workday.

\section{Methods}

\section{SUBJECTS}

\section{Groups exposed to impulse noise}

Platers and welders born in 1940 or later who had been exposed to impulse noise in the ship section assembly shop of a shipyard for three to 10 years were selected for a questionnaire survey. Ninety nine men completed a questionnaire that asked about their subjective symptoms when at work, the annoying features in their conditions of work, the physical and mental load of their jobs, and their perceived state of health. In addition, they completed the Eysenck personality inventory (EPI-C), and their subjective sensitivity to noise in general was surveyed. None of them had any occupational disease or hearing loss according to their periodical medical examinations. The results of the questionnaire will be reported separately.

Three groups of ten workers each were selected from these 99 workers. The subjects (Ss) were selected on the basis of duration of employment in conditions where they were exposed to impulse noise. The other criteria for selection were that they should be working as a plater, and their age. The aim was to select groups with a shorter (group 1), an intermediate (group 2), and a longer (group 3) duration of exposure to impulse noise. As there were not enough platers for group 1 , seven welders were included. All workers wore some sort of ear protectors, usually earmuffs (Silenta Pop or Silenta Super). Hence the workers' individual levels of noise exposure were about $15-25 \mathrm{~dB}$ lower than the measured noise levels would indicate.

Group 1 had been exposed for three to four years (mean age 24.6 years, SD 2.46), group 2 for five to six years (mean age 28.3 years, SD $2 \cdot 83$ ), and group 3 for seven to 10 years (mean age $30 \cdot 1$ years, SD $2 \cdot 23$ ). All the men worked in the same large shop on an assembly line within close proximity of each other.

The shipyard was built in 1972 and the men in groups 1 and 2 had worked only at this particular shipyard. The men of group 3 had been transferred from another shipyard when the new one was opened; they had worked at the new shipyard ever since.

\section{Group exposed to continuous steady state noise}

Twelve men from a cable factory (from a total of 43 who completed the questionnaire) exposed to steady state noise were selected in the same way as the impulse noise groups; however, their duration of exposure to noise was comparable with that of group 2 . The adjustment made it possible also to compare the effects of shorter and longer durations of exposure to impulse noise with the effects of an intermediate duration of exposure to continuous steady state noise.

The mean age of this group was 28.3 years (SD $4 \cdot 87)$. The subjects had been exposed to steady state noise, on average, for 5.42 years (SD 1.58), mostly within this cable factory. All worked in the same large shop and attended machines that drew stranded cables from rods and fine wire made of different metals. Only some of the tested workers wore ear protectors, and none used protectors for the entire workday. Most had been employed at the same factory and on the same job for the entire duration of exposure.

\section{Control group}

Ten healthy male workers from the ship drafting office of the same shipyard as the groups exposed to impulse noise served as the control group. The mean age of the controls was 23.8 years (SD 3.36). Their hearing was normal. Before selection (from a total of 38 men) they had also completed the same questionnaire as the others in order that the groups be as homogenous as possible. All the controls worked in a large open plan office.

Each of the subjects was asked to refrain from drinking alcohol or beer and from staying up late on the days before testing.

\section{LEVELS OF NOISE EXPOSURE}

The levels both of impulse noise and continuous steady state noise were measured under work conditions near the workers, recording the noise on a tape recorder for further analysis. The shop at the shipyard had several sources of noise. The background noise, which was continuous and varied between 80 $\mathrm{dB}$ and $85 \mathrm{~dB}(\mathrm{~A})$, was generated from the ventilation system and from the transformers of the welding machines. Hammering with a sledge hammer generated impulses with a build up time of several tens of milliseconds (under $100 \mathrm{msec}$ ). The peak levels were 130-140 dB, sometimes $150 \mathrm{~dB}$, with a B-duration of several hundreds of milliseconds (300-800 msec). Pneumatic scaling hammers gave rise to peak noise levels of $120-125 \mathrm{~dB}$. The strike 
Fig 1 Examples of exposure to impulse noise for groups in shipyard: (A) Impulses produced by (a) sledge hammer, (b) pneumatic chisel, (c) grinder. (B) Level recordings of impulses produced by sledge hammer (S), pneumatic chisel (P), and grinder (G); (a) slow rms, (b) fast rms, and (c) peak level.

(C) Power spectrum of a hammer blow, $T=160 \mathrm{~ms}$, (a) direct FFT, 2048 points, BT =1, (b) averaged $F F T, 128$ points, $B T=64$. (D) Examples of (a) spectra and (b) histograms for hammering chiselling - - , and grinding - . - . , latter two spectra are displaced by $-10 \mathrm{~dB}$ and $-20 \mathrm{~dB}$, respectively, for clarity. (Reproduced by the permission of the authors ${ }^{17}$ ). 
rate was 50 per second. The sound level (RMS) was $15 \mathrm{~dB}$ lower than the peak level. Grinding generated continuous noise with peaks of $115-120 \mathrm{~dB}$. The overall equivalent level of the average noise dose for 10 minute periods was $100 \mathrm{~dB}$; the lowest was $86 \mathrm{~dB}$ and the highest $111 \mathrm{~dB}$. Because of the hammering, the platers were exposed to noise with $L_{\text {eq }}$ values somewhat higher than the welders (fig 1).

The cable factory also had several sources of noise. Machines pulling rod cable generated continuous and steady state noise, the levels of which were $95 \mathrm{~dB}$ at the front end of the machine and 92 $\mathrm{dB}$ at the back. Machines pulling fine wire gave rise to noise levels of 93 and $94 \mathrm{~dB}$. Cable stranding machines generated noise levels of $92 \mathrm{~dB}$ at the middle of the machines, $91 \mathrm{~dB}$ by the work table, 89 $\mathrm{dB}$ in between the machines, and $88 \mathrm{~dB}$ between the feeding wheels. The electrical welding of copper cables generated noise levels as high as $84 \mathrm{~dB}$ in the background and $86 \mathrm{~dB}$ close to the workers. Cleaning the copper cables gave rise to levels of $82 \mathrm{~dB}$ at the cleaning pool and $84 \mathrm{~dB}$ in the background (fig 2).

\section{MEASUREMENT OF HEARING THRESHOLDS}

Hearing thresholds were measured with a manual pure tone audiometer (Madsen) three times a workday about 10 minutes after exposure on two separate weekdays. Measurements were taken immediately before going to the job site at (0700) "morning," before lunch (1030) "midday," and at the end of the workday (1530) "afternoon." Exposure to noise lasted for three hours between the morning and midday measurements, and for three and a half hours between the midday and afternoon measurements. There was a one hour lunch break after the midday measurement.

The hearing thresholds were measured in both ears at frequencies of $1,2,4,6$, and $8 \mathrm{kHz}$. The series were both descending and ascending, with steps of $5 \mathrm{~dB}$. The scale of the test tone intensities started at $-10 \mathrm{~dB}$ (sound pressure level, SPL) and ended with $80 \mathrm{~dB}$. The threshold value was defined as the specific value at which the Ss reacted by lifting the index finger of his right hand successively on at least two of the four test presentations. The right ear was always tested first, and the measurements were done by the same tester in a quiet audiometer room at the clinic of either the shipyard or the cable factory. After testing the noise level in the audiometer room, the frequency of $500 \mathrm{~Hz}$ was omitted from the threshold measurements because the background noise exceeded the highest permissible level of the ISO standard at this frequency.

Each subject had to walk about $500 \mathrm{~m}$ from his job site to the clinic for testing. The two test days
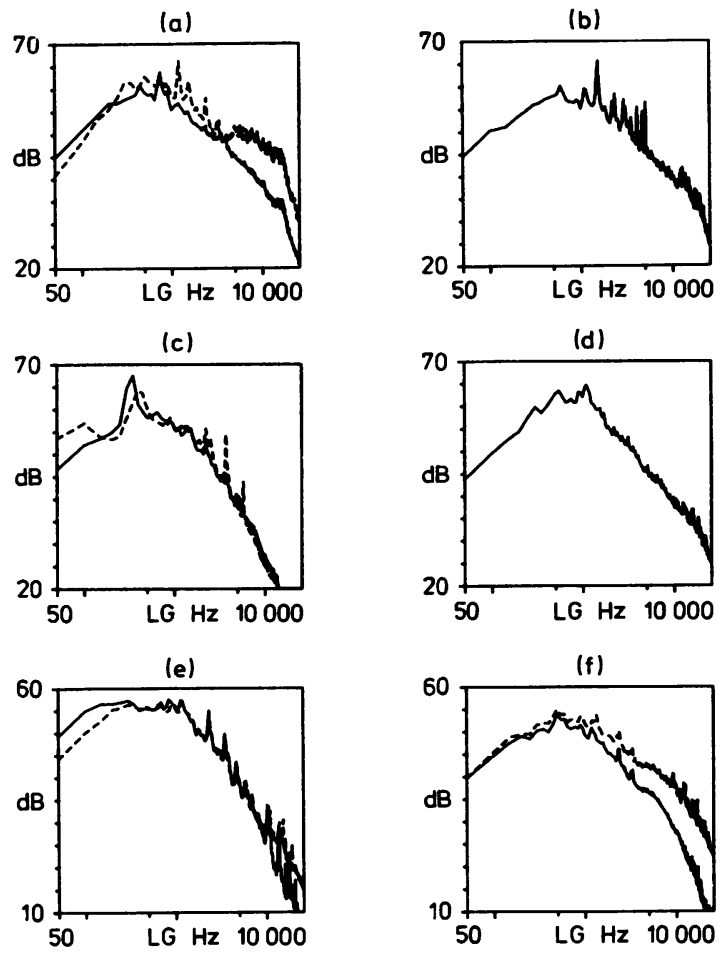

Fig 2 A-weighted spectra (PSD) of steady state noise to which group in cable factory was exposed. In (a) solid line shows noise from rod cable drawing machines at back of machines, and broken line shows it at front; (b) shows noise from machines pulling fine wires between machines; (d) at midsite of machines; and (e) by other machines of same type (solid line) and between wheels of machines (broken line). In (c) solid line shows noise from cable stranding machines by midsite, and broken line by work table; $(f)$ shows noise at background by electrical welding of copper cables (solid line), and close by worker (broken line).

were balanced so that those tested on Monday returned on Thursday. Tuesday was paired with Friday and Wednesday with the next Monday. The hearing thresholds of the control group were tested in the same manner, although the Ss in the control group began work one hour later than the exposed groups.

\section{STATISTICAL ANALYSIS}

The data from the left and right ears were analysed separately by two way analysis of variance (Anova 2 ), the F-test, and Newman-Keuls multiple comparisons test.

Two-way analysis of variance was performed using a morning, midday, and afternoon measurement as the first factor and the tested frequency as the second factor in order to see the effects of daily 
exposure within the groups. Another Anova 2 was performed using the group as the first factor and the tested frequency as the second. This Anova 2 was carried out separately for the three measurements to see whether the groups differed already in the morning measurement.

\section{Results}

\section{DIFFERENCES WITHIN THE GROUPS}

Figures 3 and 4 show the audiograms from the left and right ears, pooled from the first and second day afternoon tests. None of the groups had significant differences between the hearing thresholds measured in the morning, at midday, and in the afternoon. Each group, however, showed significant differences between the hearing thresholds of the tested frequencies in the morning, midday, and afternoon measurements in both ears $(p<0 \cdot 01)$. No significant interactions, however, were found between the measurements and the frequencies. Tables 1 and 2 give the average hearing thresholds and the standard deviations of the groups. The control group had the highest thresholds in the morning and the group exposed to continuous noise had the highest thresholds in the afternoon. The hearing thresholds of the groups exposed to impulse noise varied between the measurements. Tables 3 and 4 give the summary of the Anova 2.

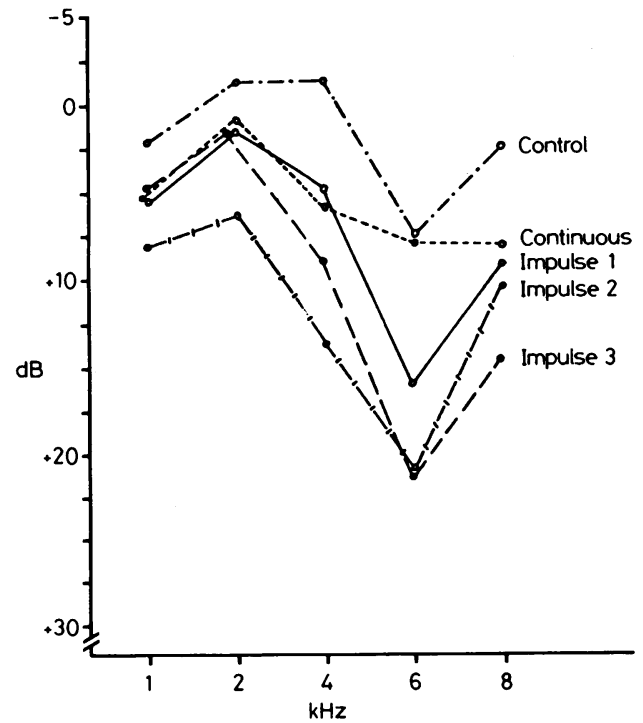

Fig 3 Average hearing thresholds of left ear of controls, three impulse noise groups (1-3), and continuous noise group at frequencies of $1000-8000 \mathrm{~Hz}$ measured in afternoon. Data are from 10 or 12 subjects in a group, pooled from two test days; standard errors have been omitted for clarity.

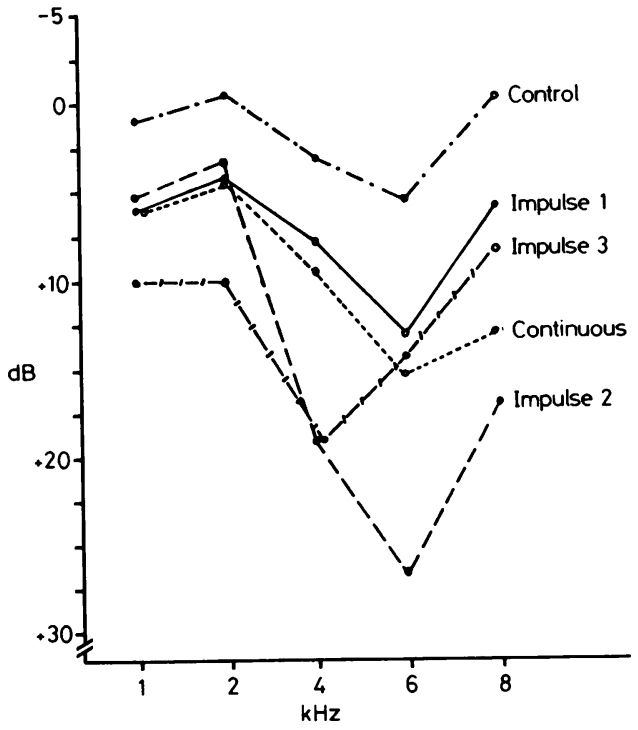

Fig 4 Average hearing thresholds of right ear of controls, three impulse noise groups (1-3), and continuous noise group at frequencies of 1000-8000 $\mathrm{Hz}$ measured in afternoon. Data are from 10 or 12 subjects in a group, pooled from two test days; standard errors have been omitted for clarity.

Since there were no significant differences within the groups between the daily measurements, only the afternoon thresholds are described here. Impulse noise group 1 had the highest thresholds at $6000 \mathrm{~Hz}(p<0.01$, F-test). In the left ear the thresholds were, on average, $13 \mathrm{~dB}$ and in the right ear $16 \mathrm{~dB}$. Impulse noise group 2 also had the highest thresholds at $6000 \mathrm{~Hz}(\mathrm{p}<0.01)$. The average values were $26.25 \mathrm{~dB}$ for the left ear and $21.25 \mathrm{~dB}$ for the right ear.

Impulse noise group 3 had the highest thresholds asymmetrically. In the left ear the values were highest at $4000 \mathrm{~Hz}$, and the height was $19.00 \mathrm{~dB}(\mathrm{p}<$ 0.01 ). In the right ear they were highest at $6000 \mathrm{~Hz}$, and, on average, $20.75 \mathrm{~dB}(\mathrm{p}<0.01)$. The group exposed to continuous noise also had the highest threshold values asymmetrically. In the left ear the highest values were found, $15.20 \mathrm{~dB}$ at $6000 \mathrm{~Hz}(\mathrm{p}$ $<0.01)$. In the right ear none of the frequencies had significantly deviating threshold values, but the thresholds were highest at $8000 \mathrm{~Hz}(7.90 \mathrm{~dB})$. Contrary to expectations, the thresholds of the control group also varied with the frequencies. The highest threshold values were found at $6000 \mathrm{~Hz}$ for the left ear $5.50 \mathrm{~dB}(\mathrm{p}<0.01)$ and $7.50 \mathrm{~dB}$ for the right ear $(p<0.01)$. All the groups had the lowest threshold values at $2000 \mathrm{~Hz}$. The mean values varied in the left ear between -0.5 and $+9.75 \mathrm{~dB}$; the control 
Table 1 Average hearing thresholds $(d B)$ of the left and right ears of the groups at frequencies of $1000-8000 \mathrm{~Hz}$ in the morning, at midday, and in the afternoon pooled from the two test days. The table shows the significant $F$-test values of the difference between the groups (df 4/99)

\begin{tabular}{|c|c|c|c|c|c|c|c|c|c|c|}
\hline \multirow{2}{*}{$\begin{array}{l}\text { Variables } \mathrm{Hz} \\
\text { Ear }\end{array}$} & \multicolumn{2}{|l|}{1000} & \multicolumn{2}{|l|}{2000} & \multicolumn{2}{|l|}{4000} & \multicolumn{2}{|l|}{6000} & \multicolumn{2}{|l|}{8000} \\
\hline & Left & Right & Left & Right & Left & Right & Left & Right & Left & Right \\
\hline $\begin{array}{l}\text { Morning: } \\
\text { Control group } \\
\text { Imp noise } 1 \\
\text { Imp noise } 2 \\
\text { Imp noise } 3 \\
\text { Cont noise } \\
\text { F }\end{array}$ & $\begin{array}{l}2 \cdot 75 \\
4 \cdot 75 \\
5 \cdot 00 \\
8 \cdot 75 \\
4 \cdot 35 \\
3.98^{* *}\end{array}$ & $\begin{array}{l}2 \cdot 00 \\
5 \cdot 75 \\
2 \cdot 50 \\
7 \cdot 50 \\
4 \cdot 40 \\
-\end{array}$ & $\begin{array}{l}0.50 \\
3.25 \\
2.75 \\
9 \cdot 00 \\
2 \cdot 10 \\
3.98^{* *}\end{array}$ & $\begin{array}{r}-2 \cdot 50 \\
1 \cdot 25 \\
2 \cdot 75 \\
5 \cdot 25 \\
0 \\
4 \cdot 65^{* *}\end{array}$ & $\begin{array}{c}4 \cdot 50 \\
7 \cdot 25 \\
20 \cdot 25 \\
18 \cdot 50 \\
10 \cdot 00 \\
6.97^{* *}\end{array}$ & $\begin{array}{r}-0.45 \\
3.50 \\
8.25 \\
12.50 \\
5.20 \\
6.97^{* *}\end{array}$ & $\begin{array}{l}5 \cdot 00 \\
12 \cdot 00 \\
29.75 \\
12 \cdot 00 \\
14 \cdot 35 \\
10.78^{* *}\end{array}$ & $\begin{array}{c}9 \cdot 75 \\
13 \cdot 00 \\
21 \cdot 75 \\
22 \cdot 50 \\
7 \cdot 10 \\
6 \cdot 70^{* *}\end{array}$ & $\begin{array}{c}-0.25 \\
7.00 \\
16.75 \\
7.00 \\
13.55 \\
6.35^{* *}\end{array}$ & $\begin{array}{c}3.50 \\
9.50 \\
15.00 \\
11.50 \\
5.40 \\
3.86^{* *}\end{array}$ \\
\hline $\begin{array}{l}\text { Midday: } \\
\text { Control group } \\
\text { Imp noise } 1 \\
\text { Imp noise } 2 \\
\text { Imp noise } 3 \\
\text { Cont noise } \\
\text { F }\end{array}$ & $\begin{array}{l}1 \cdot 00 \\
4 \cdot 50 \\
4 \cdot 75 \\
9 \cdot 50 \\
5 \cdot 00 \\
7 \cdot 31^{* *}\end{array}$ & $\begin{array}{l}2 \cdot 25 \\
5 \cdot 75 \\
3 \cdot 25 \\
8 \cdot 00 \\
3 \cdot 75 \\
3 \cdot 14^{*}\end{array}$ & $\begin{array}{c}0.50 \\
4 \cdot 50 \\
3 \cdot 75 \\
10 \cdot 00 \\
2 \cdot 90 \\
5 \cdot 30^{* *}\end{array}$ & $\begin{array}{r}-2 \cdot 00 \\
0 \cdot 25 \\
1.50 \\
5 \cdot 25 \\
-0 \cdot 20 \\
3.91^{* *}\end{array}$ & $\begin{array}{c}3 \cdot 00 \\
7 \cdot 00 \\
20 \cdot 75 \\
18 \cdot 25 \\
7 \cdot 90 \\
7 \cdot 72^{* *}\end{array}$ & $\begin{array}{c}-1.00 \\
3.25 \\
7.75 \\
12.75 \\
5.00 \\
6.85^{* *}\end{array}$ & $\begin{array}{c}5 \cdot 25 \\
11 \cdot 75 \\
27 \cdot 50 \\
14 \cdot 00 \\
14 \cdot 20 \\
7 \cdot 11^{* *}\end{array}$ & $\begin{array}{c}7 \cdot 50 \\
12 \cdot 75 \\
21 \cdot 00 \\
22 \cdot 25 \\
6 \cdot 25 \\
6 \cdot 42^{* *}\end{array}$ & $\begin{array}{c}-1 \cdot 00 \\
5 \cdot 50 \\
17 \cdot 50 \\
7 \cdot 75 \\
14 \cdot 80 \\
8 \cdot 25^{* *}\end{array}$ & $\begin{array}{c}3.00 \\
10.00 \\
14.75 \\
12.00 \\
6.05 \\
3.38^{*}\end{array}$ \\
\hline
\end{tabular}

${ }^{*} \mathrm{p}<0.05^{*},{ }^{* *} \mathrm{p}<0.01^{* *}$.

Imp $=$ Impulse

Cont $=$ Continuous.

Table 2 Standard deviations (SD) for the average hearing thresholds of the groups shown in table 1

\begin{tabular}{|c|c|c|c|c|c|c|c|c|c|c|}
\hline \multirow{2}{*}{$\begin{array}{l}\text { Variables } \mathrm{Hz} \\
\text { Ear }\end{array}$} & \multicolumn{2}{|l|}{1000} & \multicolumn{2}{|l|}{2000} & \multicolumn{2}{|l|}{4000} & \multicolumn{2}{|l|}{6000} & \multicolumn{2}{|l|}{8000} \\
\hline & Left & Right & Left & Right & Left & Right & $L e f t$ & Right & Left & Right \\
\hline $\begin{array}{l}\text { Morning: } \\
\text { Control group } \\
\text { Imp noise } 1 \\
\text { Imp noise } 2 \\
\text { Imp noise } 3 \\
\text { Cont noise }\end{array}$ & $\begin{array}{l}\text { SD } \\
4 \cdot 15 \\
4 \cdot 25 \\
4 \cdot 40 \\
6 \cdot 45 \\
5 \cdot 18\end{array}$ & \begin{aligned} \multicolumn{1}{|l}{ SD } \\
$3 \cdot 43 \\
3 \cdot 80 \\
17 \cdot 37 \\
6 \cdot 08 \\
8 \cdot 16\end{aligned}$ & $\begin{array}{r}\text { SD } \\
5 \cdot 26 \\
4 \cdot 15 \\
7 \cdot 30 \\
10 \cdot 11 \\
7 \cdot 91\end{array}$ & $\begin{array}{l}\text { SD } \\
3 \cdot 86 \\
4 \cdot 39 \\
4 \cdot 78 \\
8 \cdot 35 \\
7 \cdot 31\end{array}$ & $\begin{array}{r}\text { SD } \\
5 \cdot 49 \\
7 \cdot 31 \\
20 \cdot 20 \\
12 \cdot 93 \\
7 \cdot 38\end{array}$ & $\begin{array}{r}\text { SD } \\
2 \cdot 76 \\
5 \cdot 70 \\
10 \cdot 07 \\
8 \cdot 46 \\
10 \cdot 92\end{array}$ & $\begin{array}{l}\text { SD } \\
7 \cdot 05 \\
9 \cdot 46 \\
22 \cdot 20 \\
7 \cdot 31 \\
10 \cdot 15\end{array}$ & $\begin{array}{l}\text { SD } \\
7 \cdot 13 \\
11 \cdot 74 \\
15 \cdot 12 \\
17 \cdot 87 \\
7 \cdot 50\end{array}$ & $\begin{array}{l}\text { SD } \\
7 \cdot 18 \\
10.94 \\
20 \cdot 06 \\
7 \cdot 36 \\
9.29\end{array}$ & $\begin{array}{rr}\text { SD } & \text { N } \\
7.56 & 20 \\
14.96 & 20 \\
13.42 & 20 \\
8.61 & 20 \\
7.02 & 24\end{array}$ \\
\hline $\begin{array}{l}\text { Midday: } \\
\text { Control group } \\
\text { Imp noise } 1 \\
\text { Imp noise } 2 \\
\text { Imp noise } 3 \\
\text { Cont noise }\end{array}$ & $\begin{array}{l}3 \cdot 90 \\
3 \cdot 70 \\
4 \cdot 16 \\
6 \cdot 40 \\
5 \cdot 96\end{array}$ & $\begin{array}{l}3 \cdot 08 \\
3 \cdot 80 \\
4 \cdot 46 \\
6 \cdot 33 \\
8 \cdot 67\end{array}$ & $\begin{array}{l}4 \cdot 40 \\
3 \cdot 90 \\
5 \cdot 95 \\
9 \cdot 85 \\
7 \cdot 96\end{array}$ & $\begin{array}{l}4 \cdot 20 \\
4 \cdot 17 \\
5 \cdot 01 \\
9 \cdot 01 \\
6 \cdot 79\end{array}$ & $\begin{array}{r}6.45 \\
8 \cdot 00 \\
20 \cdot 15 \\
13 \cdot 30 \\
9.85\end{array}$ & $\begin{array}{r}3.90 \\
5 \cdot 06 \\
9.77 \\
8 \cdot 11 \\
12.80\end{array}$ & $\begin{array}{r}7 \cdot 50 \\
10 \cdot 92 \\
23 \cdot 01 \\
8 \cdot 36 \\
12 \cdot 41\end{array}$ & $\begin{array}{r}7 \cdot 40 \\
15 \cdot 37 \\
16 \cdot 49 \\
18 \cdot 26 \\
6 \cdot 20\end{array}$ & $\begin{array}{r}6 \cdot 76 \\
11 \cdot 38 \\
19.35 \\
8 \cdot 81 \\
8 \cdot 50\end{array}$ & $\begin{array}{r}7.86 \\
16.07 \\
14.06 \\
9.01 \\
8.66\end{array}$ \\
\hline $\begin{array}{l}\text { Afternoon: } \\
\text { Control group } \\
\text { Imp noise } 1 \\
\text { Imp noise } 2 \\
\text { Imp noise } 3 \\
\text { Cont noise }\end{array}$ & $\begin{array}{l}3 \cdot 78 \\
4 \cdot 55 \\
5 \cdot 25 \\
6 \cdot 45 \\
6 \cdot 00\end{array}$ & $\begin{array}{l}3 \cdot 87 \\
4 \cdot 40 \\
4 \cdot 87 \\
6 \cdot 10 \\
9 \cdot 07\end{array}$ & $\begin{array}{l}5 \cdot 69 \\
4 \cdot 20 \\
5 \cdot 56 \\
8 \cdot 87 \\
7 \cdot 74\end{array}$ & $\begin{array}{l}4 \cdot 68 \\
4 \cdot 74 \\
5 \cdot 08 \\
8 \cdot 18 \\
6 \cdot 26\end{array}$ & $\begin{array}{r}6.66 \\
7.70 \\
19.51 \\
12.18 \\
9.24\end{array}$ & $\begin{array}{r}4.62 \\
5.86 \\
10.61 \\
7.98 \\
13.70\end{array}$ & $\begin{array}{r}5 \cdot 74 \\
8 \cdot 86 \\
21 \cdot 48 \\
8 \cdot 60 \\
10 \cdot 72\end{array}$ & $\begin{array}{r}8 \cdot 10 \\
13.83 \\
16.46 \\
19.02 \\
7.33\end{array}$ & $\begin{array}{r}6.54 \\
11.00 \\
20.10 \\
9.27 \\
9.73\end{array}$ & $\begin{array}{r}6.08 \\
16.61 \\
15.06 \\
8.38 \\
9.15\end{array}$ \\
\hline
\end{tabular}

Imp $=$ Impulse.

Cont $=$ Continuous

group had the lowest values, and group 3 the highest. The corresponding values for the right ear were between -1.25 and $-6.25 \mathrm{~dB}$; again, the lowest values were found for the control group and the highest for group 3.

DIFFERENCES BETWEEN THE GROUPS

Table 3 gives the results of the Anova 2 and table 1 those of the F-test. Table 5 gives the result of the Newman-Keuls test for the data from both ears. The Anova 2 showed that the groups' hearing thresholds for both ears differed significantly $(p<0 \cdot 01)$. These differences could be seen from the morning measurement up to the afternoon measurements. The Anova 2 also showed that the frequencies differed significantly $(p<0 \cdot 01)$ with regard to the hearing 
Table $3 F$ and $p$ values for the factors measurements/ frequencies within the groups; left ear

\begin{tabular}{lrl}
\hline Factors & $F(d f 4 / 285)$ & $p<$ \\
\hline Controls: & 10.16 & 0.01 \\
$\quad$ Frequencies & 0.61 & - \\
Measurements & 0.23 & - \\
Interaction (df 8/285) & & \\
Impulse noise group 1: & 10.68 & 0.01 \\
Frequencies & 0.16 & - \\
Measurements & 0.18 & - \\
Interaction & & 0.01 \\
Impulse noise group 2: & 24.37 & - \\
Frequencies & 0.02 & - \\
Measurements & 0.06 & \\
Interaction & & - \\
Impulse noise group 3: & 13.17 & - \\
Frequencies & 0.41 & - \\
Measurements & 0.05 & - \\
Interaction & & - \\
Continuous noise group: & 24.42 & 0.01 \\
Frequencies & 0.20 & - \\
Measurements & & \\
Interaction & & \\
\hline
\end{tabular}

Table $4 \quad F$ and $p$ values for the factors groups/frequencies from the morning, midday, and afternoon measurements; left ear

\begin{tabular}{lrl}
\hline Factors & $F(d f$ 4/495) & $p<$ \\
\hline Morning: & & \\
Groups & 21.63 & 0.01 \\
Frequencies & 21.73 & 0.01 \\
Interaction (df 16/495) & 4.22 & 0.01 \\
Midday: & & \\
$\quad$ Groups & 23.73 & 0.01 \\
Frequencies & 17.56 & 0.01 \\
Interaction & 3.56 & 0.01 \\
Afternoon: & & \\
$\quad$ Groups & 24.50 & 0.01 \\
Frequencies & 19.57 & 0.01 \\
Interaction & 3.06 & 0.01 \\
\hline
\end{tabular}

thresholds for both ears. The interactions between the groups and the frequencies, however, were significant only for the left ear $(p<0.01)$. The F-test showed that the groups' thresholds for the left ear differed at all frequencies even at the start of the workday $(p<0.01)$. The groups' thresholds for the right ear also differed at every frequency (except $1000 \mathrm{~Hz}$ ) in the morning and in the afternoon.

\section{MORNING HEARING THRESHOLDS}

Since the comparisons discussed here dealt with five groups, five frequencies, two ears, and three measurements, the reader may find it helpful to consult table 5 (the summary of the Newman-Keuls test) while reading the results. The morning thresholds of none of the groups differed at $1000 \mathrm{~Hz}$ in the right ear. When the groups exposed to noise were com- pared with the control group, it could be seen that the group exposed to continuous noise had higher thresholds than the control group only in the left ear at $8000 \mathrm{~Hz}(\mathrm{p}<0.01)$. Moreover, these two groups did not differ significantly at all in the right ear thresholds. This was also the case with the control group and group 1.

Impulse noise group 2 at $4000-8000 \mathrm{~Hz}$ (in the left ear) and at $2000-8000 \mathrm{~Hz}$ (in the right ear), and group 3 at $1000-4000 \mathrm{~Hz}$ (in the left ear) and at $2000-6000 \mathrm{~Hz}$ (in the right ear) had higher thresholds than the control group ( $p<0.05-0.01)$.

When the groups exposed to noise were compared with one another, impulse noise group 2 at $4000 \mathrm{~Hz}$ and $6000 \mathrm{~Hz}$ (in the left ear) and at $6000-8000 \mathrm{~Hz}$ (in the right ear), and impulse noise group 3 at $1000-4000 \mathrm{~Hz}$ (in the left ear) and at 2000-6000 $\mathrm{Hz}$ (in the right ear) had higher thresholds than the group exposed to continuous noise ( $<<0.05-0.01)$. The group exposed to continuous noise and group 1 showed no significant differences in the right ear.

The impulse noise groups also differed from one another. Group 2 had higher thresholds than group 1 at $4000-6000 \mathrm{~Hz}$ only in the left ear, and group 3 had higher thresholds than group 1 at $1000-4000$ $\mathrm{Hz}$ (in the left ear) and at $4000-6000 \mathrm{~Hz}$ (in the right ear; $p<0.05-0.01$ ). At $1000 \mathrm{~Hz}$ and $2000 \mathrm{~Hz}$ group 3 had higher thresholds than group 2 in the left ear $(p<0.05)$, but at 6000 and $8000 \mathrm{~Hz}$ these differences were reversed: group 2 had higher thresholds than group $3(p<0 \cdot 05-0 \cdot 01)$.

\section{MIDDAY HEARING THRESHOLDS}

At midday the thresholds of the groups in the left ear did not differ much from the morning thresholds. The only change was found between the control group and impulse noise group 1. At 1000 $\mathrm{Hz}$ group 1 had higher thresholds than the control group ( $\mathrm{p}<0.05)$.

The thresholds of the right ear also showed few changes from the morning. At $1000 \mathrm{~Hz}$ group $3 \mathrm{had}$ higher thresholds than the control group at midday $(p<0.05)$. Impulse noise group 2 no longer differed significantly from the control group at $2000 \mathrm{~Hz}$, but there was still a difference at $4000-8000 \mathrm{~Hz}(\mathrm{p}<$ $0 \cdot 01$ ).

The midday differences between the group exposed to continuous noise and those exposed to impulse noise were similar to the morning differences. Group 1 had higher thresholds than the group exposed to continuous noise at $8000 \mathrm{~Hz}$ in the left ear $(p<0.05)$. In the right ear the difference found between group 2 and the group exposed to continuous noise at $8000 \mathrm{~Hz}$ in the morning disappeared. The groups exposed to impulse noise did not have higher thresholds than the group exposed to con- 
Table 5 Summary of significant p-values of the Newman-Keuls multiple comparison test for the differences of the hearing thresholds between groups. $L=$ left ear, $R=$ right ear.

\begin{tabular}{|c|c|c|c|c|c|c|}
\hline Group & $\begin{array}{l}\text { Frequencies/ } \\
\text { Measurements }\end{array}$ & $\begin{array}{l}1000 \\
L / R\end{array}$ & $\begin{array}{l}2000 \\
L / R\end{array}$ & $\begin{array}{l}4000 \\
L / R\end{array}$ & $\begin{array}{l}6000 \\
L / R\end{array}$ & $\begin{array}{l}8000 \\
L / R\end{array}$ \\
\hline $\begin{array}{l}\text { Contin } \\
\text { n }\end{array}$ & $\begin{array}{l}\text { Morning } \\
\text { Midday } \\
\text { Afternoon }\end{array}$ & $0.05 /-$ & Control gr & & & $\begin{array}{l}0.01 /- \\
0.01 /- \\
0.01 /-\end{array}$ \\
\hline $\begin{array}{l}(1) \\
\operatorname{lmp} \\
n\end{array}$ & $\begin{array}{l}\text { Morning } \\
\text { Midday } \\
\text { Afternoon }\end{array}$ & $\begin{array}{l}0.05 /- \\
0.05 /-\end{array}$ & & & & \\
\hline $\begin{array}{l}(2) \\
\text { Imp }\end{array}$ & $\begin{array}{l}\text { Morning } \\
\text { Midday } \\
\text { Afternoon }\end{array}$ & $0.05 /-$ & $-/ 0 \cdot 05$ & $\begin{array}{l}0 \cdot 01 / 0 \cdot 01 \\
0.01 / 0.05 \\
0 \cdot 01 / 0 \cdot 01\end{array}$ & $\begin{array}{l}0.01 / 0.01 \\
0.01 / 0.01 \\
0.01 / 0.05\end{array}$ & $\begin{array}{l}0.01 / 0.05 \\
0.01 / 0.05 \\
0.01 / 0.05\end{array}$ \\
\hline $\begin{array}{l}(3) \\
\text { Imp } \\
n\end{array}$ & $\begin{array}{l}\text { Morning } \\
\text { Midday } \\
\text { Afternoon }\end{array}$ & $\begin{array}{l}0.01 /- \\
0.01 / 0.05 \\
0.01 / 0.05\end{array}$ & $\begin{array}{l}0.01 / 0.01 \\
0.01 / 0.01 \\
0.01 / 0.01\end{array}$ & $\begin{array}{l}0.01 / 0.01 \\
0.01 / 0.01 \\
0.01 / 0.01\end{array}$ & $\begin{array}{l}-/ 0 \cdot 05 \\
-/ 0 \cdot 01 \\
-/ 0.05\end{array}$ & \\
\hline $\begin{array}{l}(1) \\
\operatorname{lmp} \\
n\end{array}$ & $\begin{array}{l}\text { Morning } \\
\text { Midday } \\
\text { Afternoon }\end{array}$ & & ntinuous noi & & & $0.05 /-$ \\
\hline $\begin{array}{l}(2) \\
\text { Imp } \\
n\end{array}$ & $\begin{array}{l}\text { Morning } \\
\text { Midday } \\
\text { Afternoon }\end{array}$ & & & $\begin{array}{l}0.05 /- \\
0.01 /- \\
0.01 /-\end{array}$ & $\begin{array}{l}0.01 / 0.01 \\
0.01 / 0.01 \\
0.01 / 0.05\end{array}$ & $-/ 0 \cdot 05$ \\
\hline $\begin{array}{l}\text { (3) } \\
\text { Imp } \\
\text { n }\end{array}$ & $\begin{array}{l}\text { Morning } \\
\text { Midday } \\
\text { Afternoon }\end{array}$ & $\begin{array}{l}0.05 /- \\
0.01 /-\end{array}$ & $\begin{array}{l}0.05 / 0.05 \\
0.01 / 0.05 \\
0.05 / 0.05\end{array}$ & $\begin{array}{l}0.05 / 0.05 \\
0.01 / 0.05 \\
0.01 / 0.05\end{array}$ & $\begin{array}{l}-/ 0.01 \\
-/ 0.01 \\
-/ 0.01\end{array}$ & \\
\hline $\begin{array}{l}\text { (2) } \\
\text { Imp } \\
\text { n }\end{array}$ & $\begin{array}{l}\text { Morning } \\
\text { Midday } \\
\text { Afternoon }\end{array}$ & & pulse noise & $\begin{array}{l} \\
0 \cdot 01 /- \\
0 \cdot 01 /- \\
0.01 /-\end{array}$ & $\begin{array}{l}0.01 /- \\
0.01 /- \\
0.01 /-\end{array}$ & $\begin{array}{l}0.01 /- \\
0.05 /-\end{array}$ \\
\hline $\begin{array}{l}(3) \\
\text { Imp } \\
n\end{array}$ & $\begin{array}{l}\text { Morning } \\
\text { Midday } \\
\text { Afternoon }\end{array}$ & $\begin{array}{l}0.05 /- \\
0.05 /- \\
0.05 /-\end{array}$ & $\begin{array}{l}0.05 /- \\
0.05 / 0.05 \\
0.05 / 0.05\end{array}$ & $\begin{array}{l}0.05 / 0.01 \\
0.05 / 0.01 \\
0.05 / 0.05\end{array}$ & $-/ 0.05$ & \\
\hline $\begin{array}{l}\text { (3) } \\
\text { Imp } \\
n\end{array}$ & $\begin{array}{l}\text { Morning } \\
\text { Midday } \\
\text { Afternoon }\end{array}$ & $\begin{array}{l}0.05 /- \\
0.05 /- \\
0.05 /-\end{array}$ & $\begin{array}{l}\text { pulse noise } \\
0.05 /- \\
0.05 /- \\
0.05 / 0.05\end{array}$ & & $\begin{array}{l}0.01 /- \\
0.01 /- \\
0.01 /-\end{array}$ & $\begin{array}{l}0.05 /- \\
0.05 /-\end{array}$ \\
\hline
\end{tabular}

tinuous noise systematically, but the direction of differences depended on the tested frequencies and the ear.

The differences between the groups exposed to impulse noise also changed somewhat from the morning. In the left ear thresholds the only change was that group 2 had higher thresholds than group 1 at $8000 \mathrm{~Hz}(\mathrm{p}<0.01)$ in addition to those differences already found in the morning. Between the other impulse noise groups there were no other changes from the morning in the left ear thresholds. Instead, the differences found in the right ear between groups 1 and 3 were no longer present at $6000 \mathrm{~Hz}$, but were at $2000 \mathrm{~Hz}(\mathrm{p}<0 \cdot 05)$. Groups 1 and 2 had no significant differences throughout the day in the right ear.

\section{AFTERNOON HEARING THRESHOLDS}

There were only a few changes from the midday results, mainly in the left ear at $1000 \mathrm{~Hz}$ or at 8000 $\mathrm{Hz}$. In the left ear the group exposed to continuous noise had higher thresholds than the controls at $1000 \mathrm{~Hz}$, as it also had at $8000 \mathrm{~Hz}$ in the morning (p $<0.05)$. When compared with the controls, impulse noise groups 1 and 2 also had higher thresholds than the controls at $1000 \mathrm{~Hz}(\mathrm{p}<0.05)$.

When compared with the group exposed to continuous noise, impulse noise group 1 no longer differed from it at $8000 \mathrm{~Hz}$ as it had at midday. Group 2 had differences similar to those measured at midday at $4000-6000 \mathrm{~Hz}$ when compared with the group exposed to continuous noise $(p<0.01)$. The differences between the group exposed to continuous noise and groups 2 and 3 remained the same as at midday ( $p<0.05-0.01)$, except that group 3 no longer differed at $1000 \mathrm{~Hz}$. Groups 2 and 3 no longer differed at $8000 \mathrm{~Hz}$, but they did differ at $1000-2000 \mathrm{~Hz}$ and at $6000 \mathrm{~Hz}$, as they had in the 
morning and at midday ( $\mathrm{p}<0.05)$.

In the thresholds of the right ear the differences between the controls and groups 2 and 3 remained as they had been at midday. This was also the case with the group exposed to continuous noise and group 2, and with groups 1 and 3 in the way that the groups exposed to impulse noise had higher thresholds than the controls or the group exposed to continuous noise $(p<0.05-0.01)$ : group 2 at $4000-8000 \mathrm{~Hz}$ and group 3 at $1000-6000 \mathrm{~Hz}$ compared with the control group and at $6000 \mathrm{~Hz}$ (group 2) and at $2000-6000 \mathrm{~Hz}$ (group 3) compared with the group exposed to continuous noise.

The only change from midday between the groups exposed to impulse noise was that impulse noise group 3 now had higher thresholds than group 2 at $2000 \mathrm{~Hz}(\mathrm{p}<0.05)$; this or other differences were not found earlier in the day between these two groups.

\section{Discussion}

\section{MAIN RESULTS}

We measured the hearing thresholds of three groups exposed to impulse noise, of one exposed to continuous steady state noise, and of a non-exposed group. When the data were analysed, we compared the differences both within and between the groups with regard to the hearing thresholds measured three times on two workdays.

The threshold audiograms of the groups varied with both the frequency and the duration of exposure. The audiograms of group 1 who had the shortest duration of exposure to impulse noise showed that the thresholds were highest at $6000 \mathrm{~Hz}$ symmetrically in both ears. Group 2 with the intermediate duration of exposure to impulse noise also had the highest threshold values symmetrically at 6000 $\mathrm{Hz}$. Group 3 with the longest duration of exposure to impulse noise had asymmetrical effects. The thresholds were highest in the left ear at $4000 \mathrm{~Hz}$ and in the right ear at $6000 \mathrm{~Hz}$. The groups exposed to continuous noise also had asymmetry in the highest threshold values. The right ear showed no significant differences between any frequency, but the left ear differed at $6000 \mathrm{~Hz}$. The control group was no exception in this respect, they also had the highest threshold values in both ears at $6000 \mathrm{~Hz}$. With regard to the differences between the groups, the audiograms showed, in general, that the longer the duration of exposure to noise, the higher the hearing thresholds.

\section{INTERPRETATION OF RESULTS}

The results indicate that the longer the duration of exposure to impulse noise, the wider the region of the frequencies which showed raised threshold shifts in both ears. This effect could already be seen in the threshold measurements in the morning, before the workday began. The same effect may be seen in the threshold shifts of the groups exposed to impulse noise when compared with one another. We are inclined to suggest that: (1) The effects on hearing of exposure to impulse noise for three to four years do not differ from those of exposure to continuous noise of a nearly equivalent noise level for about five years. (2) Exposure to impulse noise for five to six years can induce NIPTS both at 4000 and $6000 \mathrm{~Hz}$, but more prominently at $6000 \mathrm{~Hz}$. (3) Exposure to impulse noise for seven to 10 years may result in permanently raised thresholds within the entire range of audiometric frequencies $(1000-8000 \mathrm{~Hz})$.

Dieroff has suggested that permanent noise induced hearing shift always develops in the basal area of the cochlea, ${ }^{9}$ which means around the regions of 4000 to $6000 \mathrm{~Hz}$. He found that these two regions are sensitive to high levels of exposure to impulse noise, and considerable destruction may be seen after a short duration of exposure.

Group 1 had the shortest duration of exposure to impulse noise but, compared with the group exposed to continuous noise or with the control group, no systematic differences were found in the threshold shifts in either ear, nor were there uniform differences either at the beginning or at the end of the workday. This may indicate that the temporary threshold shift induced by impulse noise take more than three to four years to become permanent.

Impulse noise group 2 had already developed permanent threshold shifts at 4000 and $6000 \mathrm{~Hz}$ after five to six years' exposure. The thresholds of impulse noise group 3 showed that permanent threshold shifts at all the frequencies tested were induced within seven to 10 years of exposure. Gallo and Glorig ${ }^{7}$ and Burns ${ }^{11}$ have reported that most of the changes in the hearing level at 3000,4000 , and $6000 \mathrm{~Hz}$ occur initially after 15 years' exposure to steady state continuous noise. At 500, 1000, and $2000 \mathrm{~Hz}$, changes in the hearing level are essentially a linear function of the duration of exposure. Gallo and Glorig suggested that the best indicator of susceptibility to noise induced changes in the hearing level would probably be early evidence of the permanent threshold shift at $4000 \mathrm{~Hz}^{7}$

The present results did not show clearly any temporary threshold shifts during the workday when the thresholds were measured in the morning, at midday, or in the afternoon. Nor were the hearing thresholds of any of the three groups exposed to impulse noise or the group exposed to continuous noise significantly raised as a function of the duration of exposure over the two workdays. Nor did the 
controls' hearing change significantly over the workday. These findings can be further evidence that after some years of exposure to high levels of noise reversible daily temporary threshold shifts no longer occur as in the early phases of exposure or after a very short duration of exposure. Hetu and Parrot reported that they did not find that the postexposure thresholds measured at the end of the afternoon exposure differed from those measured at the end of the morning exposure. ${ }^{12}$

Despite the small group sizes the effects of exposure to impulse noise on hearing were similar to those reported by Rop et al, ${ }^{13}$ by Burns, ${ }^{11}$ and by Dieroff. 9 The group exposed to continuous noise and the control group had hearing levels similar to those reported by Gallo and Glorig7 and by Robinson and Sutton. ${ }^{14}$

The development of permanent threshold shifts in one or both ears suggests that occupational exposure to noise can induce both symmetrical and asymmetrical changes in the hearing level, depending on the duration of exposure and the range of noise. Alberti reported that workplace noise can induce asymmetrical hearing loss in a considerable proportion of patients. $^{15}$ In our study these findings could be related to the complexity of the exposure to noise and to the type of work done at the worksites. Other individual factors such as the work positions and the type of ear protectors or the way they were used might play an important part in the development of the symmetrical or asymmetrical changes in the hearing level. Dieroff remarked that even slight changes in the orientation of the head relative to the source of sound may bring about considerable differences in sound pressure at the eardrum or beyond. ${ }^{9}$

\section{SOURCES OF ERRORS}

In this study the levels of exposure to impulse noise and continuous noise were not equal and within both workplaces noise was generated from several sources. In the shipyard workshop the noise was a mixture of continuous noise and impulse noise; in the cable factory the noise was rather steady and continuous, but nevertheless had some features that could be characterised as impulse noise. When we take into account that the groups exposed to impulse noise wore ear protectors but the group exposed to continuous noise did not, the levels of noise exposure were more comparable than the noise levels measured would indicate. Hence, we concluded that the levels of noise exposures of the various groups could be compared with one another.

The effects of age on hearing could be considered as another possible source of the threshold differences found between the groups. The differences, however, were not thought to result from presbyacusis even though the workers' ages and the durations of exposure correlated significantly at $4000 \mathrm{~Hz}(r=0.40, p<0.01$, df 102). No frequencies higher than $4000 \mathrm{~Hz}$ were correlated with age. It is also evident that the longer the exposure to noise, the older the workers. It is also well known that higher frequencies (over $4000 \mathrm{~Hz}$ ) are more sensitive to the effects of the aging processes than lower frequencies. One reason for not taking the age differences of the groups into account was that the oldest noise exposed workers in our groups were in their early $30 \mathrm{~s}$, and few in number. The other reason was that group 3 was, on average, 9.3 years older than the control group, and yet the groups had no significant differences in hearing level at $8000 \mathrm{~Hz}$, although differences would be expected if age mattered. Nor was it thought reasonable to apply any procedure for age correction (to differentiate the effects of age from the effects of noise on hearing) as proposed by Robinson and Sutton. ${ }^{14}$

The fluctuations from the morning to midday and then to afternoon (or reversed) in the threshold values seen mainly at the lower frequencies in the intergroup differences could imply some amount of temporary threshold shift due to the day's exposure. Because these fluctuations were not systematic and because there were also interindividual variations within the groups, we suspected that these irregularities might originate from random variations within the Ss, and from a $5 \mathrm{~dB}$ scale of the audiometric equipment. Since the standard deviations in groups 2 and 3 were rather wide at certain frequencies, it seemed evident that besides exposure to noise individual factors such as the way earmuffs were worn in combination with work positions might have been highly important to the development of permanent changes in the level of hearing induced by impulse noise.

\section{Conclusions}

On the basis of our results we concluded that exposure to high levels of impulse noise (despite the use of ear protectors) is more detrimental to hearing than are high levels of continuous noise (even continuous with slightly impulsive features). Impulse noise seems to produce permanent threshold shifts at certain frequencies after a clearly shorter duration of exposure than continuous noise. The frequencies most sensitive to impulse noise are 4000 and 6000 $\mathrm{Hz}$. Only later, as a function of the duration of exposure, are the lower frequencies sensitised (cf also $\mathrm{Ward}^{4}$ ). Therefore, it is reasonable to assume that the qualities necessary for ear protectors to protect hearing from impulsive noise differ from those 
necessary to protect from continuous noise. ${ }^{1617}$ In future studies it would be more realistic to study not only the effects of exposure to noise but attention should be paid also to subjective characteristics and individual factors of work conditions.

We thank the workers of Valmet Shipyard for their participation and help in this study, which is one component of a research project entitled "Impulse noise: psychophysiological effects of impulse noise, and subjective annoyance of impulse noise," financed by the Academy of Finland, Research Council for Technology. We also thank J Starck, S Aatola, and J Pekkarinen, all from the Institute of Occupational Health, for their help and the measurements of noise levels at workplaces, and Mrs C Hinkkanen for correcting the English manuscript.

\section{References}

' Starck J. Melun ja valon merkitys terveydelle. Suomen Lääkärilehti 1981;22:1695-9.

${ }^{2}$ Schwetz F, Hloch Th, Schewczik R. Experimental exposure to impulse noise in the especially pathogenic impact frequency range. Acta Otolaryngol 1979;87:264-6.

${ }^{3}$ International Organisation for Standardisation. Acousticassessment of occupational noise exposure for hearing conservation purposes. Geneva: ISO, 1975. (ISO 1999.)

${ }^{4}$ Ward WD. Effects of impulse noise on hearing: summary and overview. Scand Audiol 1980;12,suppl:339-48.
${ }^{5}$ Mills JH, Gengel RW, Watson CS, Miller JD. Temporary changes of the auditory system due to exposure to noise for one or two days. Journal of the Acoustic Society of America 1970;48:524-30.

${ }^{6}$ Ward WD, Selters W, Glorig A. Exploratory studies on temporary threshold shift from impulses. J Acoust Soc Am 1961; 33:784-93.

7 Gallo R, Glorig A. Permanent threshold shift changes produced by noise exposure and aging. Am Ind Hyg Assoc J 1964; 25:237-45.

${ }^{8}$ Nixon JC, Glorig A. Noise-induced permanent threshold shift at $2000 \mathrm{cps}$ and $4000 \mathrm{cps}$. Journal of the Acoustic Society of America 1961;33:904-8.

${ }^{9}$ Dieroff H-G. The mechanism of impulse-noise induced hearing loss in industry and its resulting measuring problems. Scand Audiol 1980;12,suppl:249-56.

${ }^{10}$ Vaaranen V, Vasama M. Ammattitaudit 1980. Helsinki: Työterveyslaitos, 1980:57-8. (Katsauksia 34.)

"Burns W. Noise and man. London: William Clowes and Sons, 1973:189-228.

12 Hetu R, Parrot J. A field evaluation of noise-induced temporary threshold shift. Am Ind Hyg Assoc J 1978;39:301-11.

${ }^{13}$ Rop I, Raber A, Fisher GH. Study of hearing losses of industrial workers with occupational noise exposure using statistical methods for the analysis of qualitative data. Audiology 1979;18:181-96.

${ }^{14}$ Robinson DW, Sutton GJ. Age effects in hearing. A comparative analysis of published threshold data. Audiology 1979; 18:320-34

is Alberti PW. The significance of asymmetrical hearing thresholds in occupational hearing loss. Acta Otolaryngol 1979;87:25563.

${ }^{16}$ Nilsson R, Lindgren F. The effect of long term use of hearing protectors in industrial noise. Scand Audiol 1980;12,suppl: 204-11.

${ }^{17}$ Lahti T, Starck J. Industrial impulse noise measurements. Scand Audiol 1980;12,suppl:61-9. 